1.36)) than females (1.09 (1.03-1.17)). Among those with psoriasis, $4.1 \%$ were also diagnosed with PsA. An increased risk of $45 \%$ was found in those exposed to both psoriasis and PsA compared to the unexposed group (1.45 (1.09-1.94)). Conclusions: This study reports for the first time, an increase in fracture risk in patients with psoriasis. A higher risk was found in males than females and the risk was further increased if the patient also had PsA. These findings suggest that fracture risk assessment needs to be considered for individuals with psoriasis and PsA.

Acknowledgements: This study was funded by the National Institute for Health Research School for Primary Care Research (NIHR SPCR). CDM is funded by the National Institute for Health Research (NIHR) Collaborations for Leadership in Applied Health Research and Care West Midlands, the NIHR School for Primary Care Research and a NIHR Research Professorship in General Practice (NIHR-RP-2014-04-026). TH is funded by an NIHR Clinical Lectureship in General Practice. AAS is funded by an NIHR Postdoctoral Fellowship. The views expressed are those of the author(s) and not necessarily those of the NHS, the NIHR or the Department of Health.

Disclosure of Interest: None declared

DOI: 10.1136/annrheumdis-2017-eular.3379

\section{SAT0673 RISK AGE AND RELATIVE RISK OF CVD IN INFLAMMATORY JOINT DISEASES}

G. Wibetoe ${ }^{1}$, E. Ikdahl ${ }^{1}$, S. Rollefstad ${ }^{1}$, I. Olsen ${ }^{1}$, K. Bergsmark ${ }^{1}$, T. Kvien ${ }^{1}$ A. Salberg ${ }^{2}$, D. Soldal ${ }^{3}$, G. Bakland ${ }^{4}$, A. Lexberg ${ }^{5}$, B.T. Fevang ${ }^{6}$,

H.C. Gulseth ${ }^{7}$, G. Haugeberg ${ }^{8}$, A.G. Semb ${ }^{1} .{ }^{1}$ Diakonhjemmet Hospital, Oslo; ${ }^{2}$ Lillehammer Hospital for Rheumatic Diseases, Lillehammer; ${ }^{3}$ Hospital of Southern Norway, Kristiansand: ${ }^{4}$ University Hospital of Northern Norway, Tromsø; ${ }^{5}$ Vestre Viken Hospital, Drammen; ${ }^{6}$ Haukeland University Hospital, Bergen; ${ }^{7}$ Betanien Hospital, Skien; ${ }^{8}$ Martina Hansens Hospital, Bærum, Norway

Background: Individuals with inflammatory joint diseases (IJD) [rheumatoid arthritis (RA), axial spondyloarthritis (axSpA) and psoriatic arthritis (PsA)] have increased risk of cardiovascular disease (CVD). In the European guidelines for CVD prevention, calculation of relative risk and risk age is advised in patients with low absolute risk of fatal CVD events the next 10 years estimated by the systematic coronary risk evaluation [SCORE] algorithm; the rational being that low absolute risk may conceal high relative risk and risk ages far beyond chronological age. Thus, more patients needing intensive CVD prevention may be identified. Relative risk is a ratio comparing absolute CVD risk in a specific patient to the risk given optimal CVD risk factor levels (CVDRFs). Risk age denotes the age with similar CVD risk and optimal CVDRFs. To this date, no studies have evaluated relative risk and risk age across IJD entities, neither has the agreement between different risk age models been investigated.

Objectives: 1) Estimate relative risk and risk age across IJD entities. 2) Investigate agreement between different risk age models.

Methods: RA/axSpA/PsA patients aged $40 \leq 65$ years with low/moderate 10-year risk of fatal CVD were included from a nationwide quality assurance project implementing CVD risk assessment. Relative risk and cardiovascular risk age was calculated in accordance with risk charts published by the European Society of Cardiology (2016) and Cooney et al (2012), respectively. Vascular age was calculated by matching SCORE to estimated risk ages in accordance with Cuende et al (2010). Four different vascular age estimations were calculated, depending on whether the EULAR 1.5 multiplication factor in RA was applied (mSCORE) and if SCORE version with HDL-C (SCORE-HDL-C) was used: SCORE, SCOREHDL-c, mSCORE and mSCORE-HDL-c. Risk years beyond chronologic age, were calculated. Linear regression models were used to investigate agreement between risk age estimations.

Results: Relative risk was increased in $53 \%$ of all patients and $20 \%$ had three

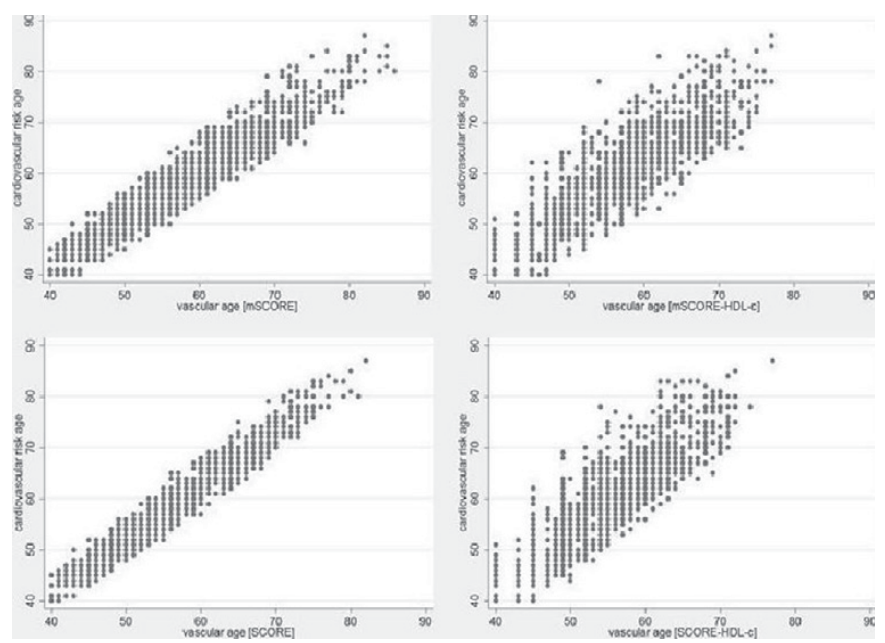

times the risk or higher compared to individuals with optimal CVDRF levels. In total, $42 \%$ and $20 \%$ had a risk age $\geq 5$ years higher than their chronologic age, according to the cardiovascular risk age model and the vascular age model derived from SCORE, respectively. There were minor differences between RA, axSpA and PsA patients in terms of relative risk and risk age. Agreement between cardiovascular risk age and various vascular age models varied (Figure). Discrepancies $\geq 5$ years in estimated risk age were observed in $14-43 \%$ of estimations. The largest observed difference in calculated risk age was 24 years. Similarly, linear regression models yielded a $\mathrm{R}^{2}$ of $0.81-0.96$. Across all models, median difference between risk age and age increased with advancing relative risk. Moreover, several patients had high relative risk despite a risk age close to their chronologic age.

Conclusions: Relative risk and risk age may identify several patients at high need of intensive CVD preventive efforts despite low estimated absolute risk. However, there are considerable discrepancies between risk age models.

Disclosure of Interest: None declared DOI: 10.1136/annrheumdis-2017-eular.2856

\section{SAT0674 EARLY TREATMENT RESPONSE TO CONVENTIONAL DMARD THERAPY IN RHEUMATOID ARTHRITIS IS A BETTER PREDICTOR OF LOW DISEASE ACTIVITY OR TREATMENT ESCALATION AT 12 AND 24 MONTHS THAN AUTOANTIBODIES OR EROSIONS}

A. Richter ${ }^{1}$, A. Strangfeld ${ }^{1}$, P. Herzer ${ }^{2}$, J. Kaufmann ${ }^{3}$, T. Klopsch ${ }^{4}$, S. Zinke ${ }^{5}$, J. Listing ${ }^{1}$, A. Zink ${ }^{1,6} .{ }^{1}$ German Rheumatism Research Center, Berlin; ${ }^{2}$ Scientific Advisory Board, Munich; ${ }^{3}$ Rheumatologist, Ludwigsfelde; ${ }^{4}$ Rheumatologist,

Neubrandenburg; ${ }^{5}$ Rheumatologist; ${ }^{6}$ Charité University Medicine, Berlin, Germany

Background: The EULAR guidelines recommend using the presence of seropositivity or erosions to support treatment decisions. The prognostic value of these factors regarding the primary treatment target in rheumatoid arthritis, remission or low disease activity (LDA), is unclear.

Objectives: To investigate biomarkers, csDMARD treatments and response to treatment regarding their usefulness to predict LDA or the need to escalate treatment within 24 month.

Methods: The control group in RABBIT (Rheumatoid Arthritis: Observation of biologic therapy) comprises $\mathrm{N}=2,228$ patients who were enrolled at treatment start with conventional-synthetic (cs)DMARDs after failure of at least one csDMARD therapy, mostly methotrexate (MTX) monotherapy. We excluded patients with a DAS28-ESR $<3.2$ at enrollment and those with $\geq 2$ csDMARD failures $(n=618)$. 102 patients were excluded due to enrollment less than 12 month prior to closure of the data base (April 30th, 2016). The DAS28-ESR, physical function, age, seropositivity $(\mathrm{RF}+/ \mathrm{ACPA}+)$, comorbidities $(\geq 3$ vs. $<3)$ and the presence of erosions at baseline were evaluated as prognostic factors. Concomitant treatment with glucocorticoids $(\mathrm{mg} / \mathrm{d}$ ) and csDMARDs, response to treatment (36 month after enrollment) were additionally examined. We applied a multinomial generalized-estimating-equation (GEE) model to investigate: (1) achievement of LDA at month 12/24 or (2) treatment escalation (biologic treatment) in year one and two after enrollment.

Results: More than one third of patients $(34.2 \%)$ were treated with a combination of MTX and leflunomide (LEF), $23.6 \%$ with LEF mono, $20.8 \%$ with MTX + hydroxychloroquine (HCQ) or sulfasalazine (SSZ), $16.5 \%$ with MTX mono, and $4.9 \%$ with SSZ mono. We found no major differences across treatment regimens except for patients treated with MTX+HCQ who had a lower DAS28, better physical function and shorter disease duration at treatment start. Significant predictors for achieving LDA were low DAS28 at baseline, improvement in DAS28 within 3-6 month, better physical function and less than 3 comorbidities (table). Escalation to bDMARD therapy was significantly more frequent in younger patients, those with no improvement in DAS28 or concomitant glucocorticoid treatment, and in patients with less than 3 comorbidities. There were no differences between treatments regarding achievement of LDA. However, switching to bDMARDs was

Table: Results of the multinomial GEE-model in odds-ratios (OR) and 95\% confidence interval (CI).

\begin{tabular}{|l|c|c|}
\hline & $\begin{array}{c}\text { Achievement of LDA } \\
\text { at month } 12 \text { or } 24\end{array}$ & $\begin{array}{c}\text { Escalation of Therapy } \\
\text { within } 12 \text { or } 24 \text { month }\end{array}$ \\
\hline Age (per 10 years) & OR $[95 \%$ CI] & OR $[95 \%$ CI] \\
\hline DAS28 improvement $\leq 6$ month (per unit) & $0.97[0.87 ; 1.07]$ & $0.77[0.70 ; 0.86]$ \\
\hline Erosions (Yes vs. No) & $0.95[0.75 ; 1.27]$ & $0.86[0.76 ; 0.97]$ \\
\hline Seropositivity (Yes vs. No) & $0.83[0.67 ; 1.02]$ & $1.16[0.86 ; 1.55]$ \\
\hline DAS at Baseline & $0.67[0.59 ; 0.76]$ & $1.14[1.00 ; 1.17]$ \\
\hline Physical function & $1.13[1.07 ; 1.19]$ & $1.04[0.97 ; 1.11]$ \\
\hline & & \\
\hline$\geq 3$ Comorbidities (vs. $<3$ comorbidities) & $0.73[0.55 ; 0.97]$ & $0.69[0.49 ; 0.98]$ \\
\hline & & \\
\hline Glucocorticoids (per 5mg/d) & $0.96[0.79 ; 1.16]$ & $1.45[1.23 ; 1.71]$ \\
\hline MTX monotherapy (Reference) & & \\
\hline LEF & $0.81[0.58 ; 1.13]$ & $1.55[1.01 ; 2.39]$ \\
\hline MTX+ HCQ | SSZ & $1.20[0.86 ; 1.66]$ & $1.19[0.74 ; 1.90]$ \\
\hline MTX+ LEF & $0.81[0.59 ; 1.11]$ & $1.85[1.24 ; 2.77]$ \\
\hline SSZ & $0.89[0.50 ; 1.59]$ & $1.47[0.74 ; 2.89]$ \\
\hline Year 2 vs. Year 1 & $1.20[0.92 ; 1.56]$ & $1.47[1.11 ; 1.96]$ \\
\hline
\end{tabular}


most frequent in patients treated with LEF mono or with LEF+MTX. The presence of erosions or seropositivity were not associated with any of the outcomes (table).

Conclusions: The highest impact on achieving LDA was found in disease activity at baseline and response to treatment within 3-6 month. The relevance of erosions and/or seropositivity regarding the prediction of a poorer outcome is disputable.

Acknowledements: RABBIT is supported by a joint, unconditional grant from AbbVie, Bristol-Myers Squibb, Celltrion, MSD Sharp \& Dohme, Pfizer, Roche, Samsung Bioepis and UCB.

Disclosure of Interest: A. Richter Consultant for: Pfizer, A. Strangfeld Speakers bureau: BMS, MSD, Pfizer, Roche, Sanofi-Aventis, P. Herzer Consultant for: AbbVie, Pfizer, J. Kaufmann: None declared, T. Klopsch: None declared, S. Zinke: None declared, J. Listing Consultant for: Sandoz, Pfizer, A. Zink Speakers bureau: AbbVie, BMS, MSD, Pfizer, Roche, UCB

DOI: 10.1136/annrheumdis-2017-eular.4979

\section{SAT0675 THE ROLE OF EROSIONS TYPICAL OF RHEUMATOID ARTHRITIS IN THE 2010 ACR/EULAR RHEUMATOID CLASSIFICATION CRITERIA: RESULTS FROM A VERY EARLY ARTHRITIS COHORT}

G.H. Brinkmann ${ }^{1,2}$, E.S. Norli ${ }^{2,3}$, P. Bøyesen ${ }^{2}$, D. van der Heijde ${ }^{4}$, L. Grøvle ${ }^{1}$, A.J. Haugen ${ }^{1}$, H. Nygaard ${ }^{5}$, O. Bjørneboe ${ }^{3}$, C. Thunem ${ }^{2}$, T.K. Kvien ${ }^{2}$, M.D. Mjaavatten ${ }^{2}$, E. Lie ${ }^{2} .1{ }^{1}$ Østfold Hospital Trust, Moss; ${ }^{2}$ Diakonhjemmet Hospital, Oslo; ${ }^{3}$ Martina Hansens Hospital, Sandvika, Norway; ${ }^{4}$ Leiden University Medical Center, Leiden, Netherlands; ${ }^{5}$ Lillehammer Hospital of Rheumatic diseases, Lillehammer, Norway

Background: A EULAR task force has proposed that in addition to the 2010 ACR/EULAR rheumatoid arthritis (RA) classification criteria (2010 RA criteria), patients can still be classified as having RA with less than 6 criteria points on the presence of $\geq 3$ joints with typical erosions on conventional radiographs of hands and feet (erosion criterion) (1).

Objectives: To determine how the EULAR definition of erosive disease contributes to the number of patients classified as RA according to the 2010 RA criteria in an early arthritis cohort.

Methods: Patients with arthritis of $<16$ weeks duration and a clinical diagnosis of RA or undifferentiated arthritis (UA) with available hand and feet radiographs were included from the Norwegian Very Early Arthritis Clinic (NOR-VEAC) study. Erosive disease was defined according to the EULAR definition accompanying the 2010 RA criteria, i.e. $\geq 3$ erosive joints (1). We calculated the additional number of patients being classified as RA based on the erosion criteria at baseline and during follow-up. Other cut-offs and the distribution of erosive joints was also examined.

Results: The current study included 289 patients (mean (SD) age 48 (14.7) years, $54.3 \%$ females, median $(25,75$ perc) duration of joint swelling $46(19.5$, 79.0 ) days). At baseline, 120 patients (41.5\%) fulfilled the 2010 RA criteria. Of the remaining 169 not fulfilling the 2010 RA criteria, 55 patients had $\geq 1$ erosive joint (40 with hand erosions, 28 with feet erosions and 13 with hand and feet erosions) and $15(5.2 \%)$ patients fulfilled the erosion criterion (Figure 1). The distribution of erosive joints in the 169 patients not fulfilling the 2010 RA criteria at baseline is shown in the table.

\begin{tabular}{lcccccc}
\hline & \multicolumn{6}{c}{ Erosive joints at baseline } \\
\cline { 2 - 7 } & PIP & MCP & Wrist & CMC + os trapezium & MTP & IP1 feet \\
\hline$\geq 1$ erosive joint $(n=55)$ & 23 & 17 & 12 & 8 & 22 & 12 \\
$\geq 2$ erosive joints $(n=27)$ & 11 & 13 & 10 & 8 & 12 & 8 \\
$\geq 3$ erosive joints $(n=15)$ & 6 & 8 & 9 & 6 & 8 & 7 \\
\hline
\end{tabular}

118 patients had radiographic follow-up at 2 years, of whom only 1 additional patient solely fulfilled the erosion criterion during follow-up ( 7 additional patients fulfilled both the 2010 criteria and the erosion criterion). Among patients with no erosions at baseline $(\mathrm{N}=74), 13(17.6 \%)$ developed erosions during follow-up (PIP joints $n=3$, MCP $n=4$, wrist $n=3, C M C$ joint $n=1$, MTP joints $n=9$ and IP1 joint in the foot $n=3$ ).

Conclusions: Among this cohort of patients with very early arthritis, $5.2 \%$ were classified as RA at baseline based solely on the erosion criterion. Of the 118 patients with 2-year follow-up data, only 1 additional patient was classified based on the erosion criterion alone during follow-up, thus, follow-up radiographs in patients with early UA do not seem to provide additional information in classifying patients with RA.

References:

[1] van der Heijde D, van der Helm-van Mil AH, Aletaha D, Bingham CO, Burmester GR, Dougados M, et al. EULAR definition of erosive disease in light of the 2010 ACR/EULAR rheumatoid arthritis classification criteria. Ann Rheum Dis2013 Apr;72(4):479-81.

Disclosure of Interest: G. Brinkmann: None declared, E. Norli: None declared, P. Bøyesen: None declared, D. van der Heijde: None declared, L. Grøvle: None declared, A. Haugen: None declared, H. Nygaard: None declared, O. Biørneboe: None declared, C. Thunem: None declared, T. Kvien Consultant for: Has received fees for speaking and/ or consulting from AbbVie, Biogen, BMS, Boehringer Ingelheim, Celltrion, Eli Lilly, Epirus, Janssen, Merck-Serono, MSD,

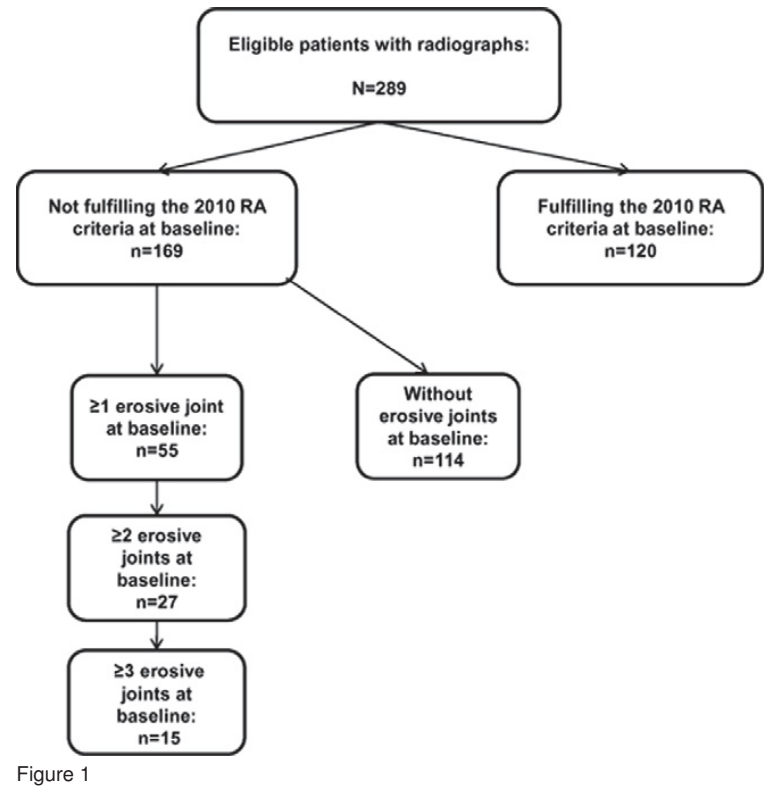

Mundipharma, Novartis, Oktal, Orion Pharma, Hospira/Pfizer, Roche, Sandoz and UCB, M. Mjaavatten: None declared, E. Lie: None declared

DOI: 10.1136/annrheumdis-2017-eular.1484

\section{SAT0676 (SERONEGATIVE) MALES SHOW BETTER EULAR TREATMENT RESPONSE THAN FEMALES IN NEWLY DIAGNOSED RHEUMATOID ARTHRITIS (RA)}

M. Yates ${ }^{1}$, J. Galloway ${ }^{1}$, A. Rivett ${ }^{2}$, S. Norton ${ }^{1}$, J.M. Ledingham ${ }^{3}$,

E.M. Dennison ${ }^{4}$, A.J. Macgregor ${ }^{5}$, K. Bechman ${ }^{1}$, A. Rutherford ${ }^{1}$, N. Snowden 6 ${ }^{1}$ Academic Rheumatology, King's College London; ${ }^{2}$ The British Society for Rheumatology, London; ${ }^{3}$ Rheumatology Dept, Portsmouth Hospitals NHS Trust, Portsmouth; ${ }^{4} \mathrm{MRC}$, Southampton University, Southampton; ${ }^{5}$ Rheumatology Dept, Norfolk and Norwich University Hospital, Norwich; ${ }^{6}$ Rheumatology Dept, Pennine MSK Partnership, Oldham, United Kingdom

Background: Gender has been reported to play a role in attainment of RA remission (1), but the data are inconsistent. The impact of gender in early RA therefore warrants further investigation.

Objectives: To assess the impact of gender on early RA outcomes.

Methods: An audit, designed as a national prospective longitudinal observational study, was conducted to assess early RA care. All NHS providers in England and Wales were required to participate. Follow up data were captured over 3 months for subjects with a diagnosis of RA. Logistic regression was used to estimate associations between gender and DAS-28 response. Smoking status, baseline disease activity, age, antibody status, symptom duration, referral times, and treatment were considered in multivariate models.

Results: 136 of 146 eligible trusts submitted data. 11,752 subjects consented, 5,622 were diagnosed with RA. DAS-28 response was available for $2234 / 5622$ $(39.7 \%)$. Male patients had a similar 3 month improvement in their DAS-28 to females, despite having a lower mean baseline score. Male gender associated with a higher rate of good EULAR response (DAS improvement $>1.2$, follow up DAS <3.3), with an adjusted odds ratio of $1.42(\mathrm{Cl} 1.17-1.72)$. There were no differences between the genders in their treatment use or in other aspects of care including speed of referral (Table 1).

Table 1

\begin{tabular}{lccc}
\hline & Male & Female & P value \\
& $\mathrm{N}=786$ & $\mathrm{~N}=1432$ & \\
\hline Age mean (SD) & $61.6(13.2)$ & $58.1(15.1)$ & $0^{\star}$ \\
Smoker \% & 28 & 21 & $0^{\star \star}$ \\
Social deprivation decile mean (SD) & $5.4(2.9)$ & $5.5(2.9)$ & $0.6^{\star \star}$ \\
Seropositive \% & 66 & 70 & $0.05^{\star \star}$ \\
symptom duration days & 230 & 226 & $0.8^{\star}$ \\
Baseline DAS-28 mean (SD) & $5.1(1.4)$ & $5.3(1.3)$ & $0.03^{\star}$ \\
FU DAS-28 mean (SD) & $3.3(1.5)$ & $3.6(1.5)$ & $0.0001^{\star}$ \\
Change in DAS-28 mean (SD) & $1.8(1.7)$ & $1.7(1.6)$ & $0.08^{\star}$ \\
EULAR good response \% & 43.4 & 36.7 & $0.002^{\star \star}$ \\
Timely referral \% & 16 & 15 & $0.3^{\star \star}$ \\
Timely rheumatology assessment \% & 39 & 39 & $0.7^{\star \star}$ \\
Steroids commenced at baseline \% & 87 & 86 & $0.7^{\star \star}$ \\
Early DMARD treatment \% & 28 & 27 & $0.9^{\star \star}$ \\
Any DMARD prescribed within 6 weeks \% & 70 & 70 & $0.9^{\star \star}$ \\
DMARD choice; Methotrexate monotherapy \% & 69 & 68 & $0.6^{\star *}$ \\
DMARD choice; combination therapy \% & 44 & 44 & $0.8^{* \star}$ \\
\hline
\end{tabular}

${ }^{*}$ t-test ${ }^{* *}$ chi-squared. Social deprivation decile from deprivation rank calculated via super output area. 